\title{
DETERMINANTS OF INVOLUNTARY PART-TIME EMPLOYMENT (A STUDY ON TURKISH SAMPLE)
}

\author{
Tekin Akgeyik, Istanbul University, Istanbul, Turkey
}

dx.doi.org/10.18374/IJBR-19-3.1

\begin{abstract}
The aim of this study is to analyze the determinants of involuntary part-time employment in Turkey using the data from the Turkish Statistical Institute (TURKSTAT) 2017 Household Labor Force Survey (HLFS). First, the results of binary logistic regression analysis showed that being male and being 35-44 years old were the determinants of involuntary part-time employment. Moreover, working in elementary occupations, having less work experience, and being informal were found to be the predictors of involuntary part-time employment. For the total sample, the regression model explained 32.9 percent of the variance in involuntary part-time employment. Also there was 15.5 percent wage difference, to the disadvantage of involuntary part-time workers.
\end{abstract}

Keywords: involuntary part-time, part-time work, part-time employment, Turkey. 